\title{
Informática na Educação: Promovendo Novos Talentos no Pampa
}

\author{
Amanda Meincke Melo, Jaline Gonçalves Mombach, Jader de Freitas Saldanha, \\ Maria Cristina Graeff Wernz
}

\author{
Universidade Federal do Pampa (Unipampa) - Campus Alegrete \\ Av. Tiarajú, 810 - Ibirapuitã - 97.546-550 - Alegrete - RS - Brasil \\ amanda.melo@unipampa.edu.br, jalinegm@gmail.com, \\ saldanha.jader@gmail.com, maria.wernz@unipampa.edu.br
}

\begin{abstract}
This paper presents experiences in the context of "Info.edu: New Talents in Pampa" subproject development, which aim at promoting the use of computing resources in Alegrete/RS public schools. Participatory design and web 2.0 resources are used as theoretical and methodological backgrounds, promoting exchanges of experiences, reflections on the use of information technology, co-authoring processes and curiosity. Results have been very positive and reinforce the importance of dialogical relationship between school and University.
\end{abstract}

Resumo. Este artigo apresenta relato de experiências no contexto de desenvolvimento do subprojeto "Info.edu: Novos Talentos no Pampa", com o objetivo de fomentar o uso de recursos de informática em escolas públicas do municipio de Alegrete/RS. Design Participativo e recursos da web 2.0 são utilizados como referenciais teórico-metodológicos, com vistas à promover trocas de experiências, reflexões sobre o uso da informática, processos de coautoria e a curiosidade. Os resultados têm sido bastante positivos e reforçam a importância da relação dialógica entre comunidade escolar $e$ universitária.

\section{Introdução}

A existência de laboratórios de informática nas escolas municipais é uma realidade (Guimarães e Sena, 2010) e o programa como o Um Computador por Aluno - UCA ${ }^{1}$ desafia professores em diferentes localidades do Brasil a reverem suas práticas pedagógicas, incluindo as mídias digitais entre seus instrumentos no trabalho para e com seus alunos. Para contribuir à inclusão digital de estudantes e à formação continuada de professores da Educação Básica, as Universidades desempenham importante papel, seja no desenvolvimento de ações de extensão ou pela oferta de Programas de PósGraduação.

É neste cenário que está em desenvolvimento o subprojeto "Info.edu: Novos Talentos no Pampa", vinculado ao Projeto Institucional Novos Talentos da UNIPAMPA (Edital n. 33/2010 - Programa Novos Talentos/CAPES) e planejado a partir de demandas de professores da Educação Básica de Alegrete/ $\mathrm{RS}^{2}$ por espaços de troca de experiências e de formação para uso de Tecnologias de Informação e Comunicação -

\footnotetext{
1 http://www.uca.gov.br/

$2 \mathrm{http} / /$ sites.google.com/site/wuiealegrete/
} 
TIC em contexto escolar. O subprojeto tem entre seus objetivos fomentar a sistematização do uso de recursos de informática em escolas públicas de Alegrete/RS alicerçada em métodos que promovam adoção significativa e autônoma da tecnologia no cotidiano escolar; também usar TIC como instrumento de construção e exercício da cidadania. Observa-se que, gradualmente, as ações de extensão promovidas têm sido incorporadas ao cotidiano da formação de professores do município, contribuindo à inclusão digital de estudantes e ao aperfeiçoamento de professores da Educação Básica.

Este artigo apresenta relato de experiência da primeira fase do subprojeto, realizada de nov/2010 a dez/2011, e está organizado como segue. Na seção 2, apresentase seu referencial teórico-metodológico. $\mathrm{Na}$ seção 3, faz-se um breve relato de experiência de ações realizadas junto a alunos e professores da Educação Básica de escolas públicas do município. Por fỉm, na seção 4, realizam-se as considerações finais.

\section{Referencial Teórico-Metodológico}

Nas ações que compõem o relato de experiências deste artigo, adota-se como referencial teórico-metodológico o Design Participativo e como instrumentos de investigação e de mediação pedagógica recursos da web 2.0.

\subsection{Design Participativo}

Trata-se de uma abordagem escandinava ao design para o ambiente de trabalho, que tem origem na década de 70 e propõe a participação ativa do usuário final no desenvolvimento de tecnologias que interferem em seu dia a dia (Grønbœk, 1991; Muller et al., 1997). Na comunidade brasileira de Computação, tem sido adotada mais recentemente como estratégia para atuar sobre o desafio "Acesso Participativo e Universal do Cidadão Brasileiro ao Conhecimento" (Almeida et al., 2009; Bonacin et al., 2009), embora sejam conhecidas experiências anteriores relacionadas ao Design para o Ambiente de Trabalho (Bonacin et al., 2003) e ao Design com Crianças (Martins et al., 2003; Melo et al., 2008).

O Design Participativo - DP favorece o exercício da democracia, a troca de experiências e conhecimentos entre os envolvidos, além da aceitação do produto final que é produzido em processos de coautoria e de negociação (Grønbœk, 1991). Apresenta-se como instrumento metodológico propício ao desenvolvimento de projetos colaborativos e para a promoção da aprendizagem pela troca de experiências entre mundo, alunos e professores em ambiente democrático de interação e de intervenção (Mombach et al., 2010; Saldanha et al., 2011). Técnicas como Braindraw, Future Workshop e Storytelling Workshop (Muller et al., 1997) são facilmente adaptadas para uso em contextos educacionais:

- Braindraw: Brainstorming gráfico, em grupo e em rodízio, no qual três a cinco participantes iniciam, cada um, o esboço de uma interface, utilizando lápis e canetas, entre outros materiais de desenho. Transcorrido um tempo (ex.: 45s), entregam sua produção para o colega à esquerda, que dá continuidade ao trabalho iniciado. Esse processo segue até que cada folha tenha passado uma ou duas vezes pelos participantes, ou até quando o grupo achar necessário. Assim, várias propostas são geradas, subsidiando a consolidação de uma única proposta que reflita as contribuições do grupo.

- Future Worskhop: Oficina em três fases que realiza uma crítica da situação 
presente, uma fantasia de uma situação futura melhor, e a forma de como sair da situação criticada para a situação fantasiada. Podem ser utilizados papel pardo, post-its (ou pedaços de papel e durex) e canetas. Auxilia na identificação de problemas e sua clarificação, além da elaboração de um plano de intervenção.

- Storytelling Workshop: Cada participante apresenta duas histórias sobre o uso de computadores, sendo uma história positiva e outra negativa. As histórias são comentadas em grupo, podendo ser evidenciadas semelhanças e contrastes entre elas. Tem-se como resultado uma melhor coesão entre os participantes e o reconhecimento que algumas dificuldades são compartilhadas.

\subsection{Recursos da Web 2.0}

Sem necessitar do envolvimento de um profissional da Computação ou de multimeios, sistemas da web 2.0 viabilizam a coautoria e a publicação por usuários finais, descentralizando os meios produtores de informação (Isotani et al., 2008). Vários dos recursos disponíveis nestes sistemas podem ser utilizados em diferentes navegadores, não apresentando dependência com sistemas operacionais. Assim, seu acesso e uso por estudantes e professores é facilitado, seja na escola, em telecentros, em casa etc.

O Blogger ${ }^{3}$, por exemplo, organiza a publicação de textos online por data de postagem, valorizando as contribuições mais recentes ao apresentá-las primeiro. $\mathrm{O}$ Google Sites ${ }^{4}$ possibilita a organização, a publicação e a manutenção de sites. O Google Docs $^{5}$ favorece a criação, a edição e o compartilhamento de documentos, planilhas, apresentações, desenhos e formulários online, inclusive de forma colaborativa, de modo síncrono ou assíncrono.

O caráter interativo da web 2.0 "contribui para o estabelecimento de intensas trocas e mediações, parte fundamental do processo de ensino/aprendizagem" (Molin, 2010). Seus recursos podem ser aliados na realização de propostas educacionais que envolvam a autoria, a comunicação em rede, a colaboração e a importante participação dos jovens na constituição da mídia (Martins et al., 2003).

\section{Relato de Experiência}

As atividades do subprojeto são organizadas em ações para estudantes e ações para professores. Entre as ações para estudantes está a reedição do projeto Gurizada.net (Mombach et al., 2010). As ações para professores envolvem laboratórios de informática, workshops e práticas participativas, propostos a partir da identificação de interesses junto a professores de escolas públicas.

Cada ação é planejada, presencialmente e a distância, e executada por integrantes do Grupo de Estudos em Informática na Educação. O grupo é composto por docentes e discentes da área de Computação (UNIPAMPA - Campus Alegrete), técnicoadministrativos em educação com formação em cursos de licenciaturas e membro da comunidade externa - professora de escola pública, que também atua no Centro de Referência em Inclusão Digital - CRID.

As ações são avaliadas pelos participantes e pela equipe de extensionistas, de

3 Disponível em: http://blogger.com/

4 Disponível em: http://sites.google.com/

5 Disponível em: http://docs.google.com/ 
forma objetiva, quanto à divulgação, à programação, à infraestrutura, à organização e aos temas abordados, além de ser realizada uma autoavaliação e serem apontadas impressões gerais e sugestões. As avaliações contribuem ao (re)planejamento de novas ações. Neste trabalho são considerados os aspectos qualitativos da avaliação.

\subsection{Gurizada.net}

Organizado em 4 encontros de 3 horas cada, no primeiro encontro do Gurizada.net esboçou-se com os participantes (14 adolescentes com idades entre 12 e 17 anos), de forma colaborativa, uma agenda de atividades (Tabela 1). Tímidos em um primeiro momento, com o auxílio da equipe de extensionistas, alguns temas de interesse foram identificados: modelagem 3D, componentes do computador, edição de imagens/vídeos e publicação de blogs ou sites.

Tabela 1. Agenda de atividades definida colaborativamente.

\begin{tabular}{|l|l|l|l|}
\hline $\mathbf{0 5} / \mathbf{0 1} / \mathbf{2 0 1 1}$ & $\mathbf{0 6 / 0 1 / 2 0 1 1}$ & $\mathbf{1 2 / 0 1 / 2 0 1 1}$ & $\mathbf{1 3 / 0 1 / 2 0 1 1}$ \\
\hline - Apresentação; & - Dinâmica de interação: & - Dinâmica de interação; & - Diálogo participativo \\
- Conversa sobre o uso que & histórias de sucesso e & - Exploração de blogs e & sobre Pirataria e Direitos \\
fazem do computador e/ou & fracasso; & sites; & Autorais; \\
Internet; & - Diálogo participativo & - Oficina de criações: & - Criação de blogs e sites; \\
- Elaboração da agenda de & sobre hardware e software; & edição de fotos e clipes; & - Encerramento. \\
atividades; & - Modelagem 3D; & - Encerramento. & \\
- Uso do laboratório; & - Encerramento. & & \\
- Encerramento. & & & \\
\hline
\end{tabular}

Levando em conta os interesses manifestados, foram organizadas dinâmicas para interação entre os participantes. Estes trocaram experiências sobre tecnologia, contando histórias de fracasso e de sucesso de uso da informática, brincando de adivinhação com palavras ligadas à informática, relatando conhecimento já adquirido sobre o tema. Dentre os participantes, dois adolescentes, que já tinham conhecimento sobre hardware, foram convidados a explicitar a diferença entre os termos hardware e software, assim como explicar o funcionamento de peças do computador.

Para trabalhar modelagem 3D, no segundo encontro, explorou-se a ferramenta Sculptris ${ }^{6}$, estimulando o potencial criativo dos participantes no desenvolvimento de suas produções (Figura 1). Na avaliação do encontro, os adolescentes manifestaram o quanto estiveram interessados nesta atividade e satisfeitos com as produções criadas, inclusive aqueles que demonstravam maior insegurança perante o computador.
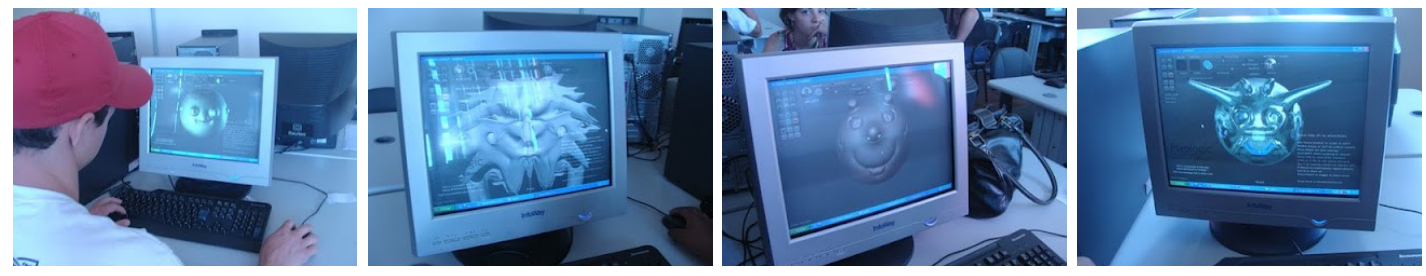

Figura 1. Produções com a ferramenta Sculptris.

No terceiro e penúltimo encontro, na oficina de criações, realizou-se edição de imagens, colagens e animações usando o software Picasa ${ }^{7}$ e os recursos do Slide.com um portal que gera animações online. Colocou-se na pauta dos dois últimos encontros, a diferença entre blog e site, além da exploração de ferramentas para sua criação, pois o grupo tinha curiosidade em conhecê-las, a fim de editar algum blog ou site futuramente.

6 Disponível em: http://www.pixologic.com/sculptris/

7 Disponível em: http://picasa.google.com/ 
Discutiu-se, ainda, temas como pirataria e direitos autorais (Tabela 2).

Tabela 2. Comentários dos adolescentes sobre direitos autorais e pirataria.

\begin{tabular}{|c|c|c|}
\hline Qual sua opinião sobre Pirataria? & $\begin{array}{l}\text { Download (baixar da internet) é } \\
\text { sempre ilegal? }\end{array}$ & $\begin{array}{l}\text { Identifique um exemplo do } \\
\text { cotidiano escolar que pode causar a } \\
\text { violação de Direitos Autorais. }\end{array}$ \\
\hline $\begin{array}{l}\text { "eu acho pirataria um orro porque as } \\
\text { pessoas sabem que não podem fazer e } \\
\text { fazem" } \\
\text { "Que é errado que as pessoas copiem } \\
\text { as ideias do outro sem que elas } \\
\text { autorizem..." }\end{array}$ & $\begin{array}{l}\text { "Nem sempre. Algumas empresas } \\
\text { autorizam o download de seus } \\
\text { softwares. Por exemplo, o Adobe, que } \\
\text { autoriza o download de alguns dos } \\
\text { seus "produtos" de graça." } \\
\text { "Não, porque existem sites em que as } \\
\text { próprias bandas disponibilizam os } \\
\text { downloads de suas músicas." }\end{array}$ & $\begin{array}{l}\text { "como no video que agente olhou e' } \\
\text { errado fazer aquilo que ele fez roubar a } \\
\text { ideia de outra pessoa" } \\
\text { "A cópia de trabalhos escolares." }\end{array}$ \\
\hline
\end{tabular}

A cada edição, o projeto Gurizada.net abre novos caminhos para seus participantes: muda o grupo, mudam os interesses, a agenda construída e as dinâmicas propostas. Trata-se de um espaço de trabalho colaborativo, de negociação, de troca entre estudantes do Ensino Superior e estudantes da Educação Básica - entre todos os envolvidos. Desperta a curiosidade dos participantes e o envolvimento com novas práticas, a partir de seus interesses e também de suas experiências pregressas; desafia ao convívio com as diferenças e à abertura ao diálogo tão necessários às práticas educativas (Freire, 1996).

\subsection{Laboratórios de Informática}

Dois laboratórios introdutórios de informática foram propostos com o intuito de atender a interesses de professores inexperientes ou pouco à vontade no uso do computador e dos recursos da web.

O Laboratório de Introdução à Informática aconteceu no dia 20 de novembro de 2010, com duração de 4 horas e público de 21 professores. Em um primeiro momento os participantes conheceram conceitos básicos de organização de computadores, periféricos e plataformas, software (sistema operacional e aplicativos) e redes de computadores - enfatizando a Internet, mecanismos de busca, web 2.0 e segurança: SPAM, anti-vírus e arquivos executáveis. Como atividade prática, exploraram o ambiente Desktop e algumas tarefas básicas, como a organização em pastas e arquivos, formas alternativas de realizar a mesma tarefa e recursos de tecnologia assistiva, além do editor de textos. A Figura 2 apresenta alguns momentos deste encontro.
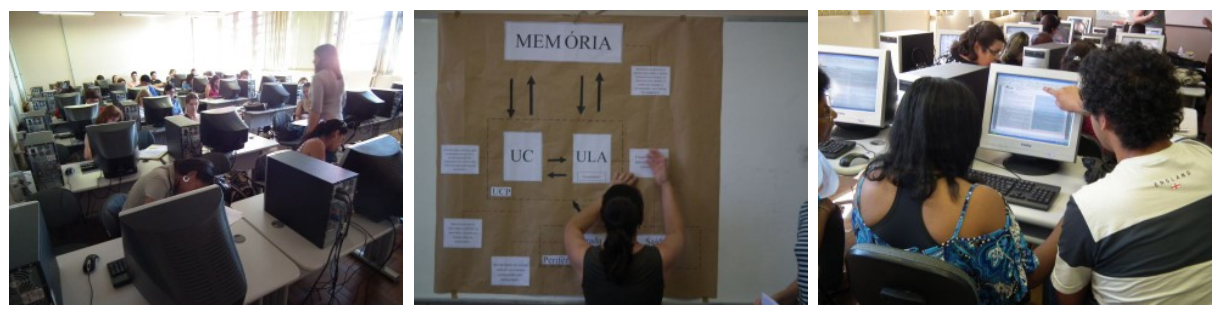

Figura 2. Momentos do Laboratório de Introdução à Informática.

Destacam-se algumas avaliações: "Foi desafiador, adorei a metodologia utilizada.", "Ótima organização, técnicas, dinamismo", "Sugiro outros encontros com atividades práticas e desafiadoras, a exemplo dessa de hoje", "O encontro foi muito 
bom, excelente material, metodologia, professores e propostas", "Gostei da equipe e espero que esse curso continue".

O Laboratório de Introdução à Web foi realizado no dia 27 de novembro de 2010 e atendeu a um grupo de 23 educadores, envolvidos durante 4 horas. Além de terem acesso a conceitos básicos da Internet, realizaram atividades teórico-práticas que apresentaram e discutiram o uso de navegadores, mecanismos de busca e a pesquisa em repositórios digitais. Ainda, os participantes que não tinham endereço de correspondência eletrônica puderam criar seu próprio e-mail. Momentos deste laboratório são apresentados na Figura 3.
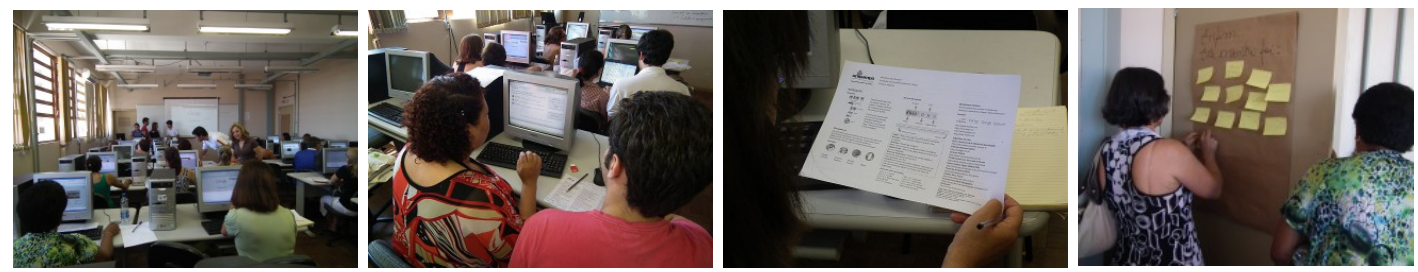

Figura 3. Momentos do Laboratório de Introdução à Web.

Destacam-se algumas avaliações: "Foi muito satisfatório o encontro, sanou várias dúvidas que possuía. Gostaria de sugerir uma mudança no horário para sábado de manhã.", "Gostaria que o curso tivesse continuidade durante as férias.", "Muito bom! A cada curso me sinto melhor e mais motivada! Obrigada.", "Sugestões: 1) Administrar blogs em sala de aula e criação de sites. 2) Como copiar vídeo do Youtube", "Ficou muito pouco tempo para a parte prática, acho que deveria ser mais direcionada as atividades, para o aprendizado ser melhor.", "Melhor impossível, espero ter a oportunidade de continuar neste programa".

A metodologia de trabalho desenvolvida no Laboratório de Introdução à Informática favoreceu a participação de usuários novatos e experientes no uso do computador, ao apresentar novas informações de foma lúdica, ao promover a troca de experiência com a equipe de extensionistas e entre os próprios participantes. Já no Laboratório de Introdução a Web, procurou-se dar continuidade à proposta. Em ambos os laboratórios, foram disponibilizados materiais de apoio impressos, o que foi bem recebido pelos participantes. Aproveitou-se o interesse demonstrado para envolvimento destes participantes em outras ações desenvolvidas no subprojeto.

\subsection{Workshops sobre Uso da Informática em Atividades de Ensino- Aprendizagem no Município de Alegrete}

Propuseram-se três workshops para professores, considerando a solicitação de reedição do evento realizado em 15/05/2010, com novas trocas de experiências e oficinas práticas (Saldanha et al., 2010). O II e o III workshops, que aconteceram respectivamente em fevereiro e julho de 2011, com 16 horas cada, contemplaram palestras, laboratórios de informática e oficina de trabalho. Já o IV workshop, realizado em setembro de 2011 e integrado à Jornada de Educação a Distância da Universidade, teve 8 horas de duração. Além de relatos de experiências locais e do programa UCA desenvolvido em Tocantis este último com recurso de webconferência -, contemplou uma mesa redonda com a participação de representante da Secretaria Municipal de Educação e Cultura, da Coordenadoria Regional de Educação, além da própria Universidade - parceira na formação continuada de professores para uso da informática na educação. A Tabela 3 apresenta a súmula da programação dos 3 workshops. 
Tabela 3. Súmula da Programação dos workshops.

\begin{tabular}{|l|l|l|}
\hline II Workshop (25 e 26/02/2011) & III Workshop (29 e 30/07/2011) & IV Workshop (24/09/2011) \\
\hline - Abertura & - Abertura & - Abertura \\
- Palestras & - Palestras & - Relatos de Experiência \\
- TIC e cidadania & - Arte e tecnologia & - Projeto UCA - Um Computador \\
- TIC e produção de textos & - Software livre e educação & Aluno, no Estado do Tocantins \\
- Informática com a Gurizada: - & Acessibilidade e inclusão digital & - Software Livre Aplicado ao Ensino \\
Design Participativo e Resolução de & - Laboratório de Informática A: & de Números Complexos \\
Problemas & Material Educacional Digital & - A Resistência dos Professores para \\
- Laboratório de Informática A: & - Laboratório de Informática B: & a Utilização da Mídia Rádio em Sala \\
Construção de Sites & Planejamento de Atividades de & de Aula \\
- Laboratório de Informática B: Web & Informática para Contexto Escolar & - Mesa Redonda: Informática na \\
2.0 & - Oficina: Trocas de Experiências, & Escola - Desafios e Perspectivas \\
- Oficina: Trocas de Experiências, & Desafios e Propostas para o Uso da & - Propostas para 2012 \\
Desafios e Propostas para o Uso da & Informática em Atividades de Ensino- & \\
Informática em Atividades de Ensino- & Aprendizagem & \\
Aprendizagem & & \\
\hline
\end{tabular}

Realizados no período de recesso escolar, a adesão dos professores ao II e ao III workshop foi bem reduzida, com participação em torno de 11 e 17 pessoas. A qualidade das discussões, entretanto, não ficou comprometida e os professores presentes aproveitaram bem as situações propostas, avaliando positivamente a dinâmica de trabalho desenvolvida e propondo novas ações - a organização das oficinas de trabalho, em particular, teve como referência a prática Future Workshop. Estes dois workshops, que valorizaram a participação de professores da comunidade escolar - inclusive como palestrantes, junto a servidores e discentes da Universidade - e promoveram a reflexão sobre a ação, influenciaram a programação do IV workshop, provocando a organização da mesa redonda com a participação de representantes da gestão local da educação e da Universidade, além de dar continuidade à valorização das experiências locais. A Figura 4 ilustra a dinâmica dos workshops.
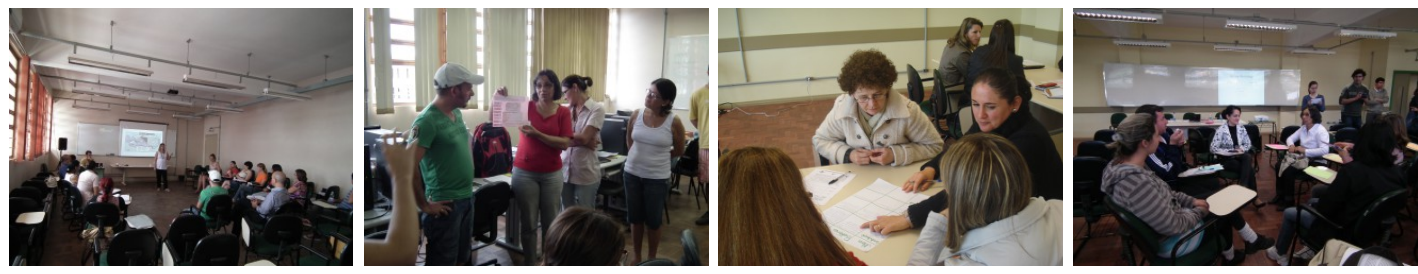

Figura 4. Momentos dos workshops.

Os workshops provocaram reflexões sobre as práticas educacionais com recursos da informática, mas também troxeram à tona aspectos sobre a gestão dos laboratórios de informática que precisam ser monitorados (ex.: ausência de conectividade com a Internet em polos rurais, manutenção dos laboratórios ainda incipiente); possibilitaram capturar novas demandas de formação por professores da Educação Básica para uso da informática na escola; indicaram a necessidade de um melhor alinhamento com as ações de formação da Secretaria Municipal de Educação e Cultura, com vistas a atingir mais professores; provocaram o desenvolvimento de ações em escolas do município (Melo et al., 2012). Ainda em 2011, novos laboratórios de informática, na temática do Software Livre, foram organizados a partir de demanda indicada pelos participantes - que têm acesso ao Linux Educacional nas escolas em que trabalham.

\subsection{Práticas Participativas}

As ações Professores.net e Encontros do Grupo de Estudos em Informática na Educação abertos a professores foram concebidas dentro de uma perspectiva participativa.

O Professores.net teve como objetivo "constituir espaço virtual para construção 
e troca de conhecimento entre mundo, professor e aluno". A organização da agenda de atividades, definida em conjunto com os participantes (Tabela 4), foi inspirada no modelo de processo da Engenharia de Usabilidade (Nielsen, 1992) com o intuito de facilitar a interlocução entre professores da Educação Básica e acadêmicos do Curso de Ciência da Computação (Melo et al., 2011; Saldanha et al., 2011). Cada um dos encontros teve duração de 3 horas, tendo participado 21 pessoas.

Tabela 4. Agenda de atividades do Professores.net.

\begin{tabular}{|l|l|l|l|}
\hline $\mathbf{1 1 / 1 2 / 1 0}$ & $\mathbf{1 8 / 1 2 / 2 0 1 0}$ & $\mathbf{1 2 / 0 3 / 2 0 1 1}$ & $\mathbf{2 6 / 0 3 / 2 0 1 1}$ \\
\hline Pré-Design & Pré-Design & Design & Design \\
- Análise de Competidores; $;$ & - Análise das Propostas & - Validação de protótipos & - Validação do design do \\
- Braindraw. & geradas no Braindraw; & em baixa fidelidade; & blog; \\
& - Consolidação dos & - Exploração de & - Edição do conteúdo do \\
& ebjetivos do espaço para & ferramentas e propostas de & espavididos em 7 \\
grupos); & - Definição da equipe \\
& editorial. \\
\hline & construção e troca de & & \\
& & & \\
\hline
\end{tabular}

Adotou-se a técnica Braindraw para geração de ideias e propostas para o espaço virtual. As propostas geradas foram analisadas e consolidadas em um único esboço, tendo em mente os seguintes objetivos: canal de divulgação - de projetos, de materiais (ex.: vídeos, arquivos PDF, fotos, músicas...); espaço de trocas - de materiais, para tirar dúvidas (ex.: Yahoo! Dúvidas), de informações; conexão com o mundo - link para outros sites, divulgação de outros projetos. Dentre os recursos da web 2.0 explorados, o sistema Blogger foi escolhido pelos participantes como ferramenta de autoria para gerar a primeira versão do espaço virtual, pela facilidade de sua estruturação em seções e atualização, além de possibilidade de "diálogo" por meio dos comentários em cada postagem. A Figura 5 ilustra a dinâmica desta ação.
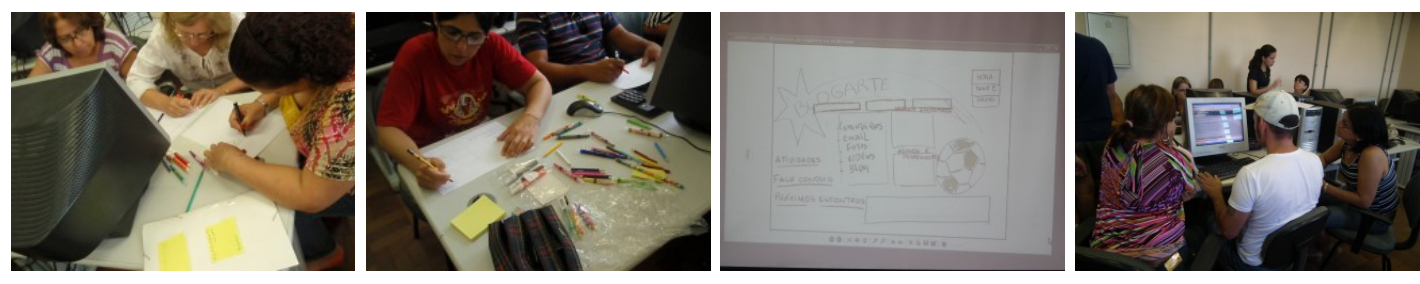

Figura 5. Momentos da ação Professores.net.

Os quatro encontros promovidos para dar início à organização de um espaço virtual que reúna os interesses da comunidade escolar e divulgue suas ações e projetos não foram suficientes para criar uma identidade de grupo para mantê-lo. Entretanto, a experiência promovida foi considerada bastante significativa pelos professores, que tiveram a oportunidade de conhecer uma prática que pode ser explorada para a construção coletiva de blogs e de sites com seus alunos.

Finalmente, a ação Encontros do Grupo de Estudos em Informática na Educação foi proposta com a intenção de compartilhar com professores da Educação Básica momentos de estudo e de reflexão sobre diversos temas ligados à Informática na Educação, permitindo aos participantes compartilharem eventuais angústias ou inseguranças relacionadas à prática pedagógica com o uso de TIC, sugerirem métodos de trabalho, dando ênfase à troca de experiências em grupo. Para isso, foram programados 4 encontros com 2 horas cada, cuja agenda de trabalho seria definida no primeiro encontro. A participação ficou em torno de 6 a 9 professores.

No primeiro encontro, em 16/04/2011, desenvolveu-se um seminário que teve 
início com a apresentação sobre a ação Professores.net na perspectiva da colaboradora externa do grupo de estudos, seguida pelo relato de experiência de um acadêmico do Curso de Ciência da Computação sobre sua participação no Grupo de Estudos em Informática na Educação, finalizando com a palestra de um docente sobre empreendedorismo na escola. Após o seminário, a proposta da ação foi apresentada aos participantes, que demonstraram interesse em serem instrumentalizados no uso de TIC. A proposta original dos encontros foi, então, revisitada para contemplar as demandas apresentadas e uma agenda foi construída em conjunto (Tabela 5).

\section{Tabela 5. Agenda definida para os Encontros do Grupo de Estudos em Informática na Educação.}

\begin{tabular}{|l|l|l|l|}
\hline $\mathbf{1 6 / 0 4 / 2 0 1 1}$ & $\mathbf{2 1 / 0 5 / 2 0 1 1}$ & $\mathbf{2 0 / 0 8 / 2 0 1 1}$ & $\mathbf{2 2 / 1 0 / 1 1}$ \\
\hline $\begin{array}{l}\text { - Seminário de abertura; } \\
\text { - Definição da agenda de } \\
\text { trabalho. }\end{array}$ & - Áudio e vídeo. & - Apresentação de slides. & $\begin{array}{l}\text { - Avaliação de softwares } \\
\text { educacionais. }\end{array}$ \\
\hline
\end{tabular}

\section{Considerações Finais}

Este artigo apresentou ações desenvolvidas no escopo do subprojeto "Info.edu: Novos Talentos no Pampa", voltadas à promoção do uso da informática por estudantes e professores da Educação Básica. Propostas a partir de demandas de professores das redes públicas municipal e estadual, foram organizadas metodologicamente com o intuito de promover trocas de experiências, reflexões sobre o uso da informática, processos de coautoria e a curiosidade, explorando o Design Participativo e recursos da web 2.0.

Criaram-se oportunidades para compartilhar com a comunidade escolar recursos que são bastante comuns no cotidiano universitário, além de abordagem que compõe o repertório de pesquisas e práticas na área de Interação Humano-Computador (IHC). Ao se perceberem protagonistas neste processo, estudantes universitários demonstraram maior interesse pela área de IHC. Há, inclusive, trabalho de conclusão de curso em desenvolvimento que explora o contexto oferecido na segunda fase de desenvolvimento deste projeto de extensão - de jan/2012 a dez/2012 (Saldanha e Melo, 2012).

De forma dinâmica e dialógica, busca-se aproximar interesses da comunidade escolar e da comunidade acadêmica. As observações realizadas pelos participantes, neste e em outros projetos de extensão desenvolvidos pelo grupo, ofereceram subsídios para o planejamento de novas ações na segunda fase do subprojeto e de novos projetos. Observa-se, ainda, que além do fomento ao uso da informática na educação, outras ações são desenvolvidas como parte do subprojeto com o intuito de promover o interesse de estudantes da Educação Básica pela carreira tecnológica e o desenvolvimento de práticas inclusivas na escola (Melo et al., 2012).

\section{Agradecimentos}

Aos integrantes do Grupo de Estudos em Informática na Educação do Campus Alegrete da UNIPAMPA e aos participantes em suas ações. Ao Programa Novos Talentos/DEBCAPES, que financia o subprojeto "Info.edu: Novos Talentos no Pampa".

\section{Referências}

Almeida, L. D. A.; Neris, V. P. A.; Miranda, L. C.; Hayashi, E. C. S.; Baranauskas, M. C. C. (2009) "Designing Inclusive Social Networks: A Participatory Approach". In: 
HCI International 2009, p. 653-662. Springer.

Bonacin, R.; Baranauskas, M. C. C.; Cecilia, R. M. (2003) Designing and Learning: joining the concepts in work practices. In Educational Technology \& Society, v. 6, n. 1, 3-8.

Bonacin, R.; Melo, A. M. ; Simoni, C. A. C.; Baranauskas, M. C. C. (2009) Accessibility and interoperability in e-government systems: outlining an inclusive development process. In Universal Access in the Information Society, v. 9, n. 1, p. 17-33.

Freire, P. (1996), Pedagogia da Autonomia: Saberes necessários à prática educativa, Paz e Terra (Coleção Leitura).

Grønbœk, K. (1991), Prototyping and active user involvement in system development: towards a cooperative prototyping approach, http://www.daimi.au.dk/ kgronbak/ Thesis/ThesisOverview.html, Fevereiro 2010.

Guimarães, T. M., Sena, R. M. (2010) "Educação e Tecnologia: práticas pedagógicas desenvolvidas nos laboratórios de informática das escolas públicas de Cáceres e região”. In XVI WIE, p. 1107-1116. SBC.

Isotani, S., Mizoguchi, R., Bittencourt, I. I., Costa, E. (2008). "Web 3.0 - os rumos da web semântica e da web 2.0 nos ambientes educacionais". In SBIE 2008, p. 785-795.

Martins, M. C., Melo, A. M., Baranauskas, M. C. C. (2003) "Participação de crianças na concepção de um portal infantil na Internet”. In IX WIE, p. 461-472. SBC.

Melo, A. M.; Baranauskas, M. C. C.; Soares, S. C. de M. (2008) Design com Crianças: da Prática a um Modelo de Processo. In Revista Brasileira de Informática na Educação, v. 16, n. 1, 43-55.

Melo, A. M, Cunha, H. S., Saldanha, J. F., Mombach, J. G. (2011) "Extensão Universitária como Prática Pedagógica de Interação Humano-Computador”. In IHC 2011/ II WEIHC.

Melo, A. M., Wernz, M. C. G., Gomes, A. G. et al. (2012). “Acessibilidade e Inclusão na Pauta de Comunidades Escolares de Alegrete". In $30^{\circ}$ SEURS.

Molin, S. I. L. (2010) "Projeto de Aprendizagem e as Ferramentas da Web 2.0: uma experiência em sala de aula". In XVI WIE, p. 1334-1353. SBC.

Mombach, J. G., Melo, A. M., Wernz, M. C. G., Saldanha, J. F., Machado, R. (2010) "Gurizada.net: inclusão digital em perspectiva participativa". In XVI WIE, p. 10691078. SBC.

Muller, M. J., Haslwanter, J. H., Dayton, T. (1997) "Participatory Practices in the Software Lifecycle". In: Handbook of Human-Computer Interaction, 2. ed., Editado por Helander, M. G., Landauer, T. K., Prabhu, P. V. Elsevier, Amsterdam, p. 255297.

Nielsen, J. The usability engineering life cycle. In Computer, Los Alamitos, v. 25, n. 3, 12-22, Mar. 1992.

Saldanha, J., Melo, A. M., Wernz, M. C. G. (2011) "Professores.net: design participativo de espaço virtual para construção e troca de conhecimento entre mundo, professor e aluno". In $5^{\circ}$ CEBEU.

Saldanha, J. F, Melo, A. M. (2012) "Qualidade no Uso de Objetos de Aprendizagem: apoio a inspeção de interface de usuário”. In IHC 2012. 